\title{
Abnormal Apical Cell Membrane in Cystic Fibrosis Respiratory Epithelium An In Vitro Electrophysiologic Analysis
}

\author{
C. U. Cotton, M. J. Stutts, M. R. Knowles, J. T. Gatzy, and R. C. Boucher \\ Division of Pulmonary Diseases, Critical Care, and Occupational Medicine, Department of Medicine, School of Medicine, \\ The University of North Carolina at Chapel Hill, Chapel Hill, North Carolina 27531
}

\begin{abstract}
The transepithelial chloride permeability of airway and sweat ductal epithelium has been reported to be decreased in patients with cystic fibrosis (CF). In the present study, we investigated whether the airway epithelial defect was in the cell path by characterizing the relative ion permeabilities of the apical membrane of respiratory epithelial cells from CF and normal subjects. Membrane electric potential difference (PD) and the responses to luminal $\mathrm{Cl}^{-}$replacement, isoproterenol, and amiloride were measured with intracellular microelectrodes. The PD across the apical barrier was smaller for CF (-11 $\mathrm{mV})$ than normal (-29 $\mathrm{mV}$ ) epithelia whereas the $P D$ across the basolateral barrier was similar, ( -26 and $-34 \mathrm{mV}$ respectively). In contrast to normal nasal epithelium, the apical membrane in CF epithelia was not $\mathrm{Cl}^{-}$permselective and was not responsive to isoproterenol. Amiloride, a selective $\mathrm{Na}^{+}$channel blocker, induced a larger apical membrane hyperpolarization and a greater increase in transepithelial resistance in $\mathrm{CF}$ epithelia. Both reduced apical cell membrane $\mathrm{Cl}^{-}$conductance and increased $\mathrm{Na}^{+}$conductance appear to contribute to the abnormal function of respiratory epithelia of CF patients.
\end{abstract}

\section{Introduction}

Sweat ductal and respiratory epithelial function of patients with cystic fibrosis $(C F)^{1}$ is abnormal $(1,2)$. The transepithelial electric potential differences (PDs) measured in vivo across both epithelia are higher than normal. The raised PD could result from an increase in transepithelial current flow (active ion transport), an increase in resistance to ion flow, or both. Measurements of biionic PDs across excised perfused sweat ducts and respiratory epithelia suggest that the relative electrodiffusive $\mathrm{Cl}^{-}$permeability of the epithelium is smaller than normal $(1,3)$. The possibility that the raised PD in respiratory epithelia also reflects in part an increased rate of $\mathrm{Na}^{+}$absorption has been proposed $(2,4)$.

Address correspondence to Dr. Boucher, University of North Carolina School of Medicine, Pulmonary Medicine, 724 Burnett-Womack Building 229H, Chapel Hill, NC 27514.

Received for publication 3 July 1985 and in revised form 17 July 1986.

1. Abbreviations used in this paper: $\psi_{\mathrm{a}}$, apical membrane voltage; $\psi_{\mathrm{b}}$, voltage across the basolateral cell membrane; $\psi_{t}$, transepithelial voltage; CF, cystic fibrosis; EMF, electromotive forces; G, transepithelial conductance; Isc, equivalent short circuit current; KBR, Krebs-bicarbonate Ringer; NT, nasal turbinate; $P D$, potential difference; $R_{a} /\left(R_{a}+R_{b}\right)$, fractional resistance of the apical membrane; $R_{t}$, transepithelial resistance.

J. Clin. Invest.

(C) The American Society for Clinical Investigation, Inc.

0021-9738/87/01/0080/06 \$1.00

Volume 79, January 1987, 80-85
Indirect evidence suggests that the cellular rather than the paracellular pathway is abnormal in the CF epithelium. In freshly excised nasal tissues, unidirectional $\mathrm{Cl}^{-}$fluxes across $\mathrm{CF}$ specimens were smaller than specimens from normal or disease control specimens (5). Because the permeability of a probe of the paracellular path $\left(\left[{ }^{14} \mathrm{C}\right]\right.$ mannitol) did not differ for $\mathrm{CF}$ and normal specimens, it was suggested that the decreased $\mathrm{Cl}^{-}$permeability of the CF epithelium was localized to the cell path. This notion has been supported by studies of cultured respiratory epithelial cells. Stutts et al. (6) demonstrated that, compared with cultured normal nasal cells, the rate of ${ }^{36} \mathrm{Cl}^{-}$influx into cultured CF nasal cells was reduced. Preliminary electrophysiologic studies of cultured normal and CF tracheal cells also may indicate that the $\mathrm{Cl}^{-}$defect resides in the cell compartment in the CF respiratory epithelium (7).

In this study we measured with intracellular microelectrodes the PDs of the apical and basolateral membranes and the ratio of apical to apical plus basolateral membrane resistance of surface epithelial cells of freshly excised CF and normal nasal epithelium. Because the major electrodiffusive paths for $\mathrm{Na}^{+}$and $\mathrm{Cl}^{-}$movement across respiratory epithelial cells are located in the apical membrane $(8,9)$, we studied the effects of drugs and changes in solution composition that affect this barrier. Nasal epithelium was selected for this study because its ion transport and permeability properties resemble those of lower airways (2). In addition, it is the only respiratory epithelium of CF subjects that is readily available and is usually not infected.

\section{Methods}

Normal nasal turbinate from six healthy patients $(27.7 \pm 2.9 \mathrm{yr})$ undergoing reconstructive surgery and nasal polyps from six $C F$ subjects $(11.7 \pm 1.3$ yr) and two atopic subjects ( 24 and $31 \mathrm{yr}$ ) were resected for clinical indications. Submucosal connective tissue was removed by sharp dissection and the tissue was pinned apical surface upwards as a diaphragm across the aperture $\left(0.20 \mathrm{~cm}^{2}\right)$ of a lucite chamber. The tissue was supported by a nylon mesh. The apical and submucosal surfaces were continuously bathed by warmed and oxygenated solutions (see below for composition). The transepithelial PD was measured between two 3-M $\mathrm{KCl}$ agar bridges in the luminal and submucosal solutions. The bridges were connected to a high impedance electrometer (model M4A; World Precision Instruments, New Haven, CT) by calomel half cells. A microelectrode was connected to a high impedance electrometer (model M707; World Precision Instruments) and placed in the luminal solution. The serosal bridge served as a common ground for the electrodes. Impalements were made across the apical cell membrane with the aid of manual micromanipulators. Transepithelial voltage $\left(\psi_{t}\right)$ and the voltage across the basolateral cell membrane $\left(\psi_{\mathrm{b}}\right)$ were monitored on an oscilloscope (model R5103N; Tektronix Inc., Beaverton, OR) and continuously recorded by a dual channel chart recorder (model 1202; Linear Instruments Corp., Irvine, CA). Apical membrane voltage $\left(\psi_{\mathrm{a}}\right)$ was calculated as the difference between $\psi_{\mathrm{b}}$ and $\psi_{\mathrm{t}}$. Transepithelial current pulses were passed between chloridized silver wires in the luminal and submucosal solutions. The silver wires were connected to a stimulator and constant current pulses $\left(30-70 \mathrm{uA} / \mathrm{cm}^{2}\right)$ of $500 \mathrm{~ms}$ were passed at 5-s intervals. The transepithelial resistance $\left(R_{t}\right)$ and the fractional resistance 
of the apical membrane $\left[R_{a} /\left(R_{a}+R_{b}\right)\right]$ were calculated from the voltage deflections $\left(\Delta \psi_{\mathrm{t}}, \Delta \psi_{\mathrm{a}}\right.$, and $\left.\Delta \psi_{\mathrm{b}}\right)$ produced in response to the constant current pulse. The resistance of the bathing solution between the bridges was subtracted. The equivalent short-circuit current was calculated from the $R_{t}$ and the spontaneous open circuit voltage (Isc $=\psi_{t} / R_{t}$ ). Because the current voltage relationship is linear with no time-dependent components over the range of voltage measured in this study, the equivalent short-circuit current reflects the current associated with net (active) fluxes at zero $\psi_{\mathrm{t}}$.

Acceptance of an impalement required that each of the following criteria be met: (a) a sharp voltage deflection, $(b)$ a stable plateau of at least 10-s duration, and $(c)$ a return of the recorded potential to within $2 \mathrm{mV}$ of the preimpalement value upon withdrawal of the microelectrode from the cell. Prolonged cellular impalements ( $>3 \mathrm{~min}$ ) were occasionally obtained and gave values for $\psi_{a}, \psi_{b}$, and $R_{a} /\left(R_{a}+R_{b}\right)$ similar to values recorded during shorter impalements. Micropipettes were prepared from borosilicate glass $(1.0 \mathrm{~mm}$ outer diameter, $0.5 \mathrm{~mm}$ inner diameter, World Precision Instruments) with a vertical pipette puller (David Kopf Instruments, Inc., Tujunga, CA). The pipettes were filled with $4 \mathrm{M}$ potassium acetate and had resistances (immersed in bathing solution) of 1540 mega $\Omega$. A number of impalements (at least eight per tissue) were made with the tissue bathed on both sides by control bathing solution. After a solution change or drug treatment, additional impalements were begun when the transepithelial PD stabilized ( $<1 \mathrm{~min})$. The impalements (at least six per tissue) were usually completed within 20 min after drug addition or ion substitution. No pattern of time-dependent changes in the electrical parameters was noted during this interval. The following sequence of maneuvers was applied to most tissues: control (Krebs-bicarbonate Ringer; $\mathrm{KBR}$ ), low luminal $\mathrm{Cl}^{-}$, control (KBR), amiloride, low $\mathrm{Cl}^{-}$plus amiloride, low luminal $\mathrm{Cl}^{-}$plus amiloride plus isoproterenol, and amiloride plus isoproterenol. Tissues were studied for 4-6 h. Other studies of excised normal and CF nasal tissue have shown that the transepithelial electric properties are stable for 6-8 $\mathrm{h}$ (unpublished observation).

Solutions and drugs. KBR contained $122 \mathrm{mM} \mathrm{NaCl}, 22 \mathrm{mM}$ $\mathrm{NaHCO}_{3}, 3 \mathrm{mM} \mathrm{KHCO} 3,0.6 \mathrm{mM} \mathrm{K}_{2} \mathrm{HPO}_{4}, 1.5 \mathrm{mM} \mathrm{KH}_{2} \mathrm{PO}_{4}, 1.5 \mathrm{mM}$ $\mathrm{CaCl}_{2}$, and $5 \mathrm{mM}$ glucose. $\mathrm{Cl}^{-}$was reduced from 125 to $3 \mathrm{mM}$ by replacement with gluconate. Isoproterenol bitartrate was obtained from Sigma Chemical Co. (St. Louis, MO); amiloride was a gift of Merck, Sharpe \& Dohme Div., Merck \& Co., Inc. (West Point, PA).

\section{Results}

The $\psi_{\mathrm{t}}$ for six normal nasal turbinates (NT) was $-6 \pm 2 \mathrm{mV}$, whereas the mean $\psi_{\mathrm{t}}$ of six CF polyps was $-15 \pm 2 \mathrm{mV}$. A similar difference in PD was previously reported for normal and CF nasal, tracheal, and bronchial $P D$ in vivo and nasal $P D$ in vitro $(2,5)$. The transepithelial conductances (G) of NT and CF polyps were not significantly different, $11.4 \pm 1.0$ and $12.6 \pm 2.1 \mathrm{mS} / \mathrm{cm}^{2}$, respectively. In a previous report from this laboratory, CF polyps were found to have a significantly smaller conductance than normal turbinate (5). However, the difference in $\mathrm{G}$ was not evident when the study was extended to a larger number of tissues (35 normal and 56 CF tissues) (4). The equivalent short-circuit current $\left(\right.$ Isc $\left.=\psi_{t} / R_{t}\right)$ was $58 \pm 18 \mathrm{uA} / \mathrm{cm}^{2}$ for NT and $170 \pm 17$ $\mathrm{uA} / \mathrm{cm}^{2}$ for CF polyps. The greater Isc of CF tissues agrees with recent data from a larger number of specimens that demonstrated that the active $\mathrm{Na}^{+}$flux reflected by the steady-state Isc for $\mathrm{CF}$ polyps $\left(146 \pm 11 \mathrm{uA} / \mathrm{cm}^{2}, n=56\right)$ is significantly greater than the Isc of NT (77 $\left.\pm 5 \mathrm{uA} / \mathrm{cm}^{2}, n=35\right)(4)$.

Fig. 1 illustrates the $\psi_{\mathrm{t}}$ trace and a representative cellular impalement. The voltage deflections result from transepithelial current pulses. Although the impalement was short (30 s), the changes were abrupt and the voltage was relatively stable during the impalement. Fig. 2 is a histogram of $\psi_{\mathrm{b}}$ of untreated tissues bathed by KBR. The data include at least 12 impalements per
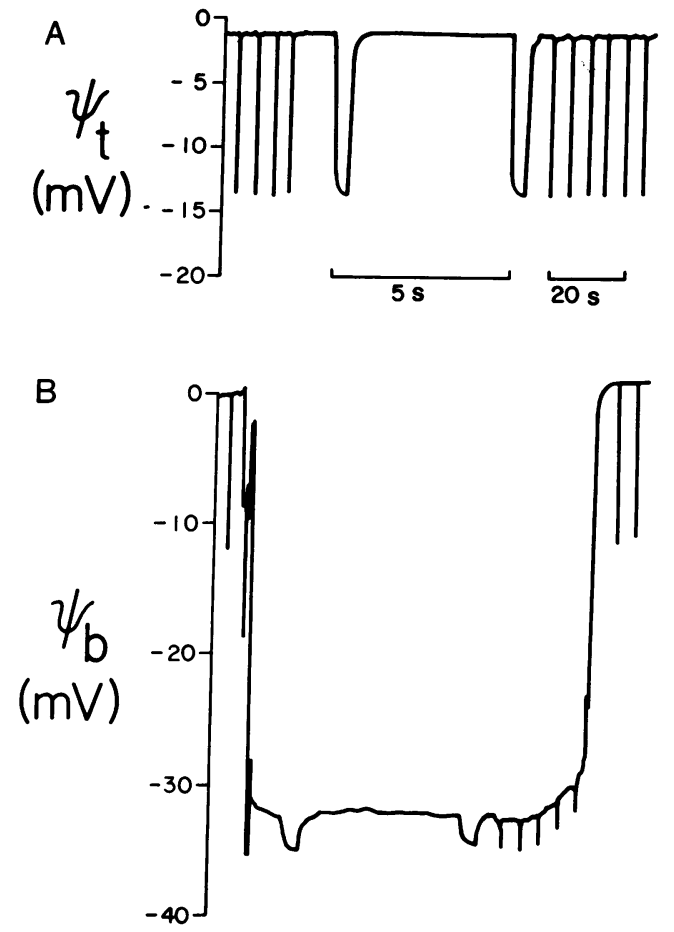

Figure 1. Tracing of a record of a representative cellular impalement of a normal nasal turbinate. $(A)$ Transepithelial potential $\left(\psi_{t}\right) .(B)$ (offset $5 \mathrm{~s}$ behind $\psi_{\mathrm{t}}$ ) Voltage sensed by the microelectrode as it is advanced into the cell $\left(\psi_{\mathrm{b}}\right)$. The voltage deflections result from transepithelial current pulses at 5-s intervals.

tissue. The unimodal distribution of $\psi_{\mathrm{b}}$ in both groups of tissues is compatible with the impalement of a single cell type. Photomicrographs of CF and normal nasal epithelial specimens from this study showed that the surface epithelium was populated mostly with ciliated cells $(>80 \%)$ in agreement with previous studies (5). For both CF and normal tissues $\psi_{\mathrm{b}}$ was not correlated with $\psi_{\mathrm{t}}$. Histograms of $\psi_{\mathrm{a}}$ for each tissue also tended to be unimodal, but the magnitude of $\psi_{\mathrm{a}}$ depended upon the specimen.

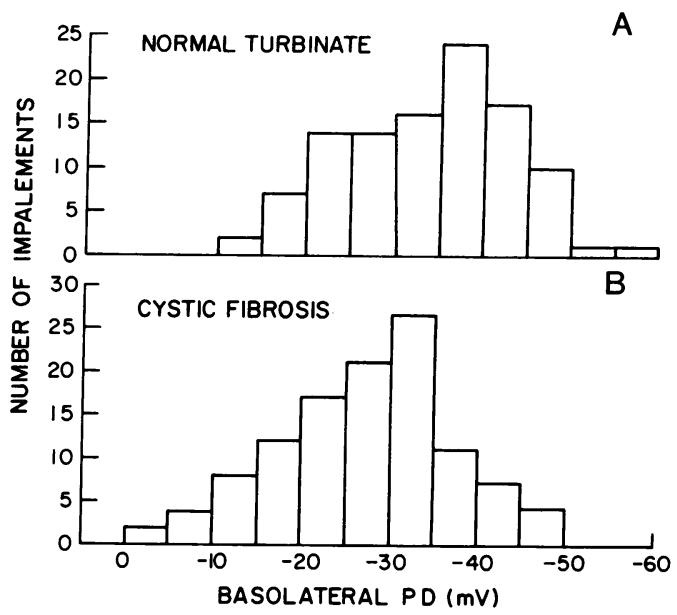

Figure 2. Basolateral membrane potentials $\left(\psi_{\mathrm{b}}\right)$ of normal nasal turbinate and nasal polyps removed from patients with cystic fibrosis. Tissues were bathed with KBR on both sides. $(A) \psi_{\mathrm{b}}$ for 106 impalements in nasal turbinate from six normal patients, $(B) \psi_{\mathrm{b}}$ for 112 impalements in nasal polyps removed from six CF patients. 
Table I shows the membrane potentials and $R_{a} /\left(R_{a}+R_{b}\right)$ of NT and CF polyps under basal conditions. The major difference between the two tissues was the smaller $\psi_{\mathrm{a}}$ of CF polyps. The $\psi_{b}$ and $R_{a} /\left(R_{a}+R_{b}\right)$ of the two groups were not significantly different.

Replacement of luminal sodium chloride by sodium gluconate induced a large transepithelial hyperpolarization in NT. The $28-\mathrm{mV}$ apical membrane $\left(\psi_{\mathrm{a}}\right)$ depolarization is consistent with the presence of a conductive permeability of the apical barrier that is greater for $\mathrm{Cl}^{-}$than gluconate. The basolateral membrane of NT also depolarized significantly, indicating that the resultant current loop was driven by the bi-ionic PD (gluconate versus $\mathrm{Cl}^{-}$) across the apical membrane rather than by that of the paracellular path (see Discussion). The steady-state $\mathbf{R}_{\mathrm{a}} /\left(\mathbf{R}_{\mathrm{a}}+\mathbf{R}_{\mathrm{b}}\right)$ was not changed. The changes in $\psi_{\mathrm{t}}$ and $\psi_{\mathrm{a}}$ of CF tissues were significantly smaller than those of NT. $\psi_{b}$ and $\mathbf{R}_{a} /\left(\mathbf{R}_{a}+\mathbf{R}_{b}\right)$ were unchanged. Return to $\mathrm{Cl}^{-}$-replete media reversed the effects of low $\mathrm{Cl}^{-}$on NT and CF polyps.

The smaller response of $\mathrm{CF}$ polyps to luminal $\mathrm{Cl}^{-}$substitution could reflect a larger apical membrane $\mathrm{Na}^{+}$permeability, rather than a smaller $\mathrm{Cl}^{-}$permeability. To evaluate this possibility, the contribution of the apical $\mathrm{Na}^{+}$permeability to the voltage response induced by luminal $\mathrm{Cl}^{-}$reduction was eliminated by pretreating tissues with amiloride, an inhibitor of the apical $\mathrm{Na}^{+}$ conductance, followed by exposure of the lumen to low $\mathrm{Cl}^{-}$ solutions containing amiloride (see below for the effects of amiloride alone). The magnitude of the apical membrane voltage drop induced by the reduction of $\mathrm{Cl}^{-}$concentration in amiloridetreated NT (Table II) was similar to that of NT not exposed to amiloride (Table I). No significant changes in $\psi_{\mathrm{a}}$ for CF or $R_{a} /\left(R_{a}+R_{b}\right)$ for either group were noted. Consequently, it is likely that the $\mathrm{Cl}^{-}$permeability of the apical cell membrane is smaller in $\mathrm{CF}$ tissues.

Beta adrenergic agonists increase $\mathrm{Cl}^{-}$secretion by $\mathrm{Cl}^{-}$-secreting epithelia (canine trachea and bullfrog cornea) by raising apical membrane $\mathrm{Cl}^{-}$conductance $(9,10)$. Because intracellular $\mathrm{Cl}^{-}$activity in $\mathrm{Cl}^{-}$-secreting epithelia is above electrochemical equilibrium (11), diffusive efflux is enhanced or induced by raising the apical $\mathrm{Cl}^{-}$conductance $(9,12,13)$. In five NT tissues that were treated with amiloride to block $\mathrm{Na}^{+}$absorption and bathed bilaterally with KBR, a small hyperpolarization in $\psi_{\mathrm{t}}$ was induced by isoproterenol (Table III). Also the equivalent Isc increased, $\psi_{a}$ depolarized, and $\mathbf{R}_{a} /\left(\mathbf{R}_{a}+\mathbf{R}_{b}\right)$ decreased significantly. These observations indicate that $\mathrm{Cl}^{-}$secretion can be stimulated in NT, in part via an action on the apical membrane.
In a similar protocol with four $\mathrm{CF}$ tissues, isoproterenol exposure failed to alter $\psi_{t}$, Isc, $\psi_{a}$, or $\mathbf{R}_{a} /\left(\mathbf{R}_{a}+\mathbf{R}_{b}\right)$ (see Table III).

We also investigated whether activation of the apical membrane $\mathrm{Cl}^{-}$conductance by isoproterenol could be detected in CF tissues by recording the response of that membrane to isoproterenol during an imposed $\mathrm{Cl}^{-}$gradient, i.e., during the exposure to low $\mathrm{Cl}^{-}$concentrations in the luminal bath (Table IV). Four CF and five NT tissues were treated with isoproterenol in the presence of low luminal $\mathrm{Cl}^{-}$and amiloride. In NT, isoproterenol induced hyperpolarization of $\psi_{t}$, a small depolarization of $\psi_{\mathrm{a}}$, and a small decrease in $\mathbf{R}_{\mathrm{a}} /\left(\mathbf{R}_{\mathrm{a}}+\mathbf{R}_{\mathrm{b}}\right)$. This provides strong evidence for an isoproterenol-stimulated apical membrane $\mathrm{Cl}^{-}$ conductance. No effects of isoproterenol were detected in CF polyps treated in a comparable manner (Table IV).

To estimate the relative magnitudes of the apical membrane $\mathrm{Na}^{+}$-electrodiffusive permeabilities for NT and CF polyps, tissues were exposed to amiloride in the presence of bilateral KBR (Table V). Amiloride decreased $\psi_{\mathrm{t}}$ and conductance in NT. A residual equivalent Isc of $17 \pm 5 \mathrm{uA} / \mathrm{cm}^{2}$ was noted in NT during amiloride exposure. The amiloride-induced reduction in $\psi_{\mathrm{t}}$ and conductance $\left(G_{t}\right)$ were larger in CF tissues than in NT. The residual Isc was smaller in CF $\left(9 \pm 3 \mathrm{uA} / \mathrm{cm}^{2}\right)$. The amiloride-induced hyperpolarization of $\psi_{a}$ and increase in $R_{a} /\left(R_{a}+R_{b}\right)$ in CF polyps were larger than recorded in NT.

The responses of the two atopic polyps to $\mathrm{Cl}^{-}$substitution, amiloride, and isoproterenol paralleled those of NT.

\section{Discussion}

Our intracellular microelectrode data suggest that the elevated $\psi_{t}$ in CF is a reflection of an abnormality of the transcellular rather than the paracellular path for transepithelial ion flow. These studies, which focused on the apical cell barrier, have detected abnormalities of this membrane that contribute to the abnormal electrical profile of the CF airway epithelial cell.

The smaller $\psi_{\mathrm{a}}$ in CF tissues could result from different properties of the apical, basolateral, or paracellular paths. The possibilities include: different relative ion permeabilities at either membrane, intracellular ion activities, membrane or paracellular resistances, and electrogenic pumps. The major apical membrane ion conductances $\left(G^{\text {ion }}\right)$ in the most widely studied model airway epithelium, canine trachea, are $\mathrm{G}^{\mathrm{Cl}^{-}}$and $\mathrm{G}^{\mathrm{Na}^{+}}(8,9,13)$. If this observation is true for human nasal epithelium, then the reduced value for $\psi_{\mathrm{a}}$ in CF tissues is consistent with either a reduced $\mathrm{G}^{\mathrm{Cl}^{-}}$(i.e., $\psi_{\mathrm{a}}$ is depolarized relative to the transmembrane chem-

Table I. Effect of Reducing Luminal $\left[\mathrm{Cl}^{-}\right]$on Transepithelial and Intracellular Electric Parameters of Normal and CF Nasal Epithelium

\begin{tabular}{|c|c|c|c|c|c|c|c|}
\hline Tissue & Luminal bathing solution & Isc & $\psi_{\mathrm{t}}$ & $\psi_{\mathrm{a}}$ & $\psi_{b}$ & G & $R_{a} /\left(R_{a}+R_{b}\right)$ \\
\hline & & $u A / \mathrm{cm}^{2}$ & $m V$ & $m V$ & $m V$ & $\mathrm{mS} / \mathrm{cm}^{2}$ & \\
\hline \multirow{2}{*}{$\begin{array}{l}\text { Normal nasal turbinate } \\
\quad(n=6)\end{array}$} & KBR & $58 \pm 18$ & $-6 \pm 2$ & $-29 \pm 4$ & $-34 \pm 4$ & $11.4 \pm 1.0$ & $0.56 \pm 0.05$ \\
\hline & Low $\mathrm{Cl}^{-}$ & - & $-19 \pm 4^{*}$ & $-1 \pm 7^{*}$ & $-20 \pm 4^{*}$ & $7.5 \pm 1.1^{*}$ & $0.57 \pm 0.06$ \\
\hline \multirow[t]{2}{*}{ CF nasal polyps $(n=6)$} & KBR & $170 \pm 17^{\ddagger}$ & $-15 \pm 2^{\ddagger}$ & $-11 \pm 3^{\ddagger}$ & $-26 \pm 2$ & $12.6 \pm 2.1$ & $0.59 \pm 0.02$ \\
\hline & Low $\mathrm{Cl}^{-}$ & - & $-22 \pm 1^{* \S}$ & $-4 \pm 5^{* \S}$ & $-26 \pm 4^{8}$ & $9.6 \pm 2.0^{*}$ & $0.57 \pm 0.02$ \\
\hline
\end{tabular}

Values represent mean $\pm \mathrm{SE}$ of steady-state potential and resistance. The serosal bathing solution was at all times KBR. The luminal bathing solution is indicated. Low $\mathrm{Cl}^{-}$was prepared by replacing $\mathrm{NaCl}$ with $\mathrm{Na}$ gluconate. * Significant change induced by replacement of luminal $\mathrm{Cl}^{-}$ (paired). ${ }^{\ddagger}$ Value for CF tissues is significantly different from normal tissues (unpaired). ${ }^{\S}$ Change induced by low $\mathrm{Cl}^{-}$solution is significantly different between the two tissue groups (unpaired). 
Table II. Effect of Reducing Luminal $\left[\mathrm{Cl}^{-}\right]$in the Presence of Amiloride on Transepithelial and Intracellular Electric Parameters of Normal and CF Nasal Epithelium

\begin{tabular}{llllllll}
\hline Tissue & Luminal bathing solution & Isc & $\psi_{\mathrm{t}}$ & $\psi_{\mathrm{a}}$ & $\psi_{\mathrm{b}}$ & $\mathrm{G}$ & $\mathrm{m}$ \\
\hline & & $u A / \mathrm{cm}^{2}$ & $m V$ & $m V$ & $m V$ & $m S / \mathrm{cm}^{2}$ \\
Normal nasal turbinate & $\mathrm{KBR}+$ amiloride & $17 \pm 5$ & $-2 \pm 1$ & $-38 \pm 3$ & $-39 \pm 2$ & $10.8 \pm 1.9$ & $0.57 \pm 0.07$ \\
$\quad(n=6)$ & Low Cl + amiloride & - & $-10 \pm 1^{*}$ & $-20 \pm 7^{*}$ & $-30 \pm 7^{*}$ & $8.0 \pm 1.8^{*}$ & $0.66 \pm 0.05$ \\
CF nasal polyps $(n=6)$ & $\mathrm{KBR}+$ amiloride & $9 \pm 3$ & $-1 \pm 0$ & $-31 \pm 3$ & $-32 \pm 3$ & $9.2 \pm 2.1$ & $0.69 \pm 0.04$ \\
& Low Cl + amiloride & - & $-4 \pm 1^{* \ddagger}$ & $-34 \pm 5^{\ddagger}$ & $-37 \pm 5^{\ddagger}$ & $7.5 \pm 1.7$ & $0.73 \pm 0.05$
\end{tabular}

Values represent mean $\pm \mathrm{SE}$ of steady-state potential and resistance. The serosal bathing solution was at all times KBR. The luminal bathing solution is indicated. Low $\mathrm{Cl}^{-}$was prepared by replacing $\mathrm{NaCl}$ with $\mathrm{Na}$ gluconate and amiloride was added to a final concentration of $10^{-4} \mathrm{M}$. ${ }^{*}$ Significant change induced by replacement of luminal $\mathrm{Cl}^{-}$(paired). ${ }^{\ddagger}$ Change induced by low $\mathrm{Cl}^{-}$solution is significantly different between the two tissue groups (unpaired).

ical potential for $\left.\mathrm{Cl}^{-}\left[\mathrm{E}^{\mathrm{Cl}^{-}}\right]\right)$and/or an increase in $\mathrm{G}^{\mathrm{Na}^{+}}\left(\mathrm{E}^{\mathrm{Na}^{+}}\right.$ has not been determined; however, it is almost certainly a positive value). Amiloride treatment resulted in a larger absolute and relative decrease in $G_{t}$, associated with a larger increase in $\mathbf{R}_{\mathrm{a}} /\left(\mathbf{R}_{\mathrm{a}}+\mathbf{R}_{\mathrm{b}}\right)$, in CF polyp than in NT (Table V). Taken together with the larger $\mathrm{Na}^{+}$transport in $\mathrm{CF}$ tissues, these findings are consistent with a larger apical membrane electrodiffusive $\mathrm{Na}^{+}$ conductance in CF as compared with NT. However, additional information about apical, basolateral, and paracellular resistances and intracellular ion activities is required to establish this notion unequivocally.

In the presence of other permeabilities, it is more difficult to firmly establish that CF nasal epithelia have an absolutely smaller $\mathrm{Cl}^{-}$conductance in the apical membrane by ion substitution approaches. However, because no satisfactory blocker of the apical electrodiffusive permeability for $\mathrm{Cl}^{-}$is available, we resorted to ion substitution experiments for an initial assessment of the relative magnitude of the $\mathrm{Cl}^{-}$conductance in $\mathrm{CF}$ and normal tissues. Ideally, the voltage response to an ion substitution should be made rapidly to minimize changes in cellular ion activities and recorded continuously so that any secondary responses to the maneuver may be avoided. Because it was difficult to obtain prolonged impalements, it was not possible to obtain information on the time course for the development of the responses. Despite this limitation, our findings indicate a $\mathrm{Cl}^{-}$-electrodiffusive permeability characterizes the apical membrane of NT and that this permeability is smaller or absent in CF. For example, reduction of the $\mathrm{Cl}^{-}$concentration of the solution bathing the apical membrane induced a large depolarization of $\psi_{\mathrm{a}}$ in NT, consistent with a bi-ionic PD across this barrier. The depolarization of $\psi_{\mathrm{a}}$ in CF polyps was smaller (Table I). Because these experiments were performed under open circuit conditions, Thevenin equivalent electromotive forces (EMFs) generated by the $\mathrm{Cl}^{-}$concentration gradients imposed by reduction of the $\mathrm{Cl}^{-}$ concentration at the apical barrier and paracellular shunt would be expected to generate current loops through the epithelium. The depolarization of $\psi_{b}$ in NT induced by a decrease in luminal $\left[\mathrm{Cl}^{-}\right]$is consistent with an intraepithelial current loop generated by a $\mathrm{Cl}^{-}$EMF at the apical membrane. Because $\psi_{\mathrm{b}}$ was unaffected in CF cells, either the paracellular or apical membrane resistance is sufficiently large to prevent intraepithelial current loops or the paracellular and apical membrane $\mathrm{Cl}^{-}$EMFs are of similar magnitude.

The pattern of responses to luminal $\mathrm{Cl}^{-}$reduction for NT and CF tissues was repeated after amiloride pretreatment (Table II). Because amiloride removes the contribution of the $\mathrm{Na}^{+}$conductance to $\psi_{\mathrm{a}}$, we would have predicted that the apical membrane would be more $\mathrm{Cl}^{-}$permselective and consequently the depolarization of $\psi_{\mathrm{a}}$ induced by low $\mathrm{Cl}^{-}$should be larger after amiloride. Failure to observe this result could reflect changes in other ion permeabilities $\left(\mathrm{K}^{+}, \mathrm{HCO}_{3}^{-}\right)$or an interaction between the $\mathrm{Na}$ and $\mathrm{Cl}$ conductances, e.g., a voltage dependence of the $\mathrm{Cl}^{-}$conductance (14). The observation, however, that in $\mathrm{CF}$ tissues the $\mathrm{Cl}^{-}$substitution maneuver induced smaller changes in $\psi_{\mathrm{a}}, \psi_{\mathrm{b}}$, and $\psi_{\mathrm{t}}$ in the presence of amiloride suggests that the electrodiffusive $\mathrm{Cl}^{-}$permeability is absolutely smaller in CF polyps than NT.

When a conductive species $\left(\mathrm{Cl}^{-}\right)$is removed from the solution bathing a membrane, the resistance of that barrier, and consequently $R_{a} /\left(R_{a}+R_{b}\right)$, should change. We cannot account for

Table III. Effect of Isoproterenol on Electrical Properties of Amiloride Pretreated Normal and CF Nasal Epithelium

\begin{tabular}{|c|c|c|c|c|c|c|c|c|}
\hline Tissue & $\begin{array}{l}\text { No. of } \\
\text { tissues }\end{array}$ & $\begin{array}{l}\text { Basolateral } \\
\text { bathing solution }\end{array}$ & Isc & $\psi_{\mathrm{t}}$ & $\psi_{\mathrm{a}}$ & $\psi_{b}$ & G & $R_{a} /\left(R_{a}+R_{b}\right)$ \\
\hline & & & $u A / \mathrm{cm}^{2}$ & $m V$ & $m V$ & $m V$ & $\mathrm{mS} / \mathrm{cm}^{2}$ & \\
\hline \multirow[t]{2}{*}{ Normal nasal turbinate } & 5 & Without Iso & $20 \pm 1$ & $-2 \pm 1$ & $-38 \pm 3$ & $-39 \pm 2$ & $11.7 \pm 2.0$ & $0.54 \pm 0.08$ \\
\hline & 5 & With Iso & $46 \pm 2^{*}$ & $-4 \pm 1^{*}$ & $-28 \pm 2^{*}$ & $-31 \pm 3$ & $12.3 \pm 2.4$ & $0.42 \pm 0.05^{*}$ \\
\hline \multirow[t]{2}{*}{ CF nasal polyps } & 4 & Without Iso & $5 \pm 1$ & $-1 \pm 1$ & $-37 \pm 1$ & $-38 \pm 1$ & $5.8 \pm 0.9$ & $0.74 \pm 0.08$ \\
\hline & 4 & With Iso & $4 \pm 1$ & $-1 \pm 1$ & $-42 \pm 5$ & $-43 \pm 5$ & $5.8 \pm 1.0$ & $0.74 \pm 0.12$ \\
\hline
\end{tabular}

Values represent mean $\pm \mathrm{SE}$ of steady-state potential and resistance from at least five impalements per tissue under each condition. The "without Iso" values reflect the steady-state values after return from exposure to reduced $\mathrm{Cl}^{-}$luminal solution (see Discussion). The mucosal solution was KBR plus amiloride and the serosal solution was with or without Iso. Iso, isoproterenol. The concentrations of amiloride and isoproterenol were $10^{-4}$ and $10^{-5} \mathrm{M}$, respectively. * Significant change induced by Iso (paired). 
Table IV. Effect of Isoproterenol on the Response of Amiloride-treated Normal and CF Nasal Epithelium to Reduced Luminal Cl

\begin{tabular}{|c|c|c|c|c|c|c|c|}
\hline Tissue & No. of tissues & Condition & $\psi_{\mathrm{t}}$ & $\psi$ & $\psi_{\mathrm{b}}$ & G & $R_{d} /\left(R_{a}+R_{b}\right)$ \\
\hline & & & $m V$ & $m V$ & $m V$ & $\mathrm{mS} / \mathrm{cm}^{2}$ & \\
\hline \multirow[t]{2}{*}{ Normal nasal turbinate } & 5 & Low $\mathrm{Cl}^{-}$ & $-10 \pm 1$ & $-20 \pm 7$ & $-30 \pm 7$ & $8.0 \pm 1.8$ & $0.66 \pm 0.05$ \\
\hline & 5 & Low $\mathrm{Cl}^{-}+$Iso & $-15 \pm 2^{*}$ & $-9 \pm 7^{*}$ & $-23 \pm 6$ & $8.5 \pm 1.9$ & $0.57 \pm 0.06^{*}$ \\
\hline \multirow[t]{2}{*}{ CF nasal polyps } & 4 & Low $\mathrm{Cl}^{-}$ & $-4 \pm 1$ & $-33 \pm 6$ & $-37 \pm 5$ & $6.2 \pm 1.8$ & $0.73 \pm 0.07$ \\
\hline & 4 & Low $\mathrm{Cl}^{-}+$Iso & $-4 \pm 1$ & $-32 \pm 6$ & $-36 \pm 5$ & $6.3 \pm 1.8$ & $0.73 \pm 0.05$ \\
\hline
\end{tabular}

Values represent mean \pm S.E. of steady-state potential and resistance from at least five impalements per tissue under each condition. The mucosal solution was low $\mathrm{Cl}^{-}$plus amiloride and the serosal solution was $\mathrm{KBR}$ with or without Iso. The concentrations of amiloride and Iso were $10^{-4}$ and $10^{-5} \mathrm{M} /$ liter, respectively. Iso, isoproterenol. * Significant change induced by Iso (paired).

the lack of an increase in $\mathbf{R}_{\mathbf{a}} /\left(\mathbf{R}_{\mathbf{a}}+\mathbf{R}_{\mathbf{b}}\right)$ after luminal $\mathrm{Cl}^{-}$reduction in NT. One possibility for which there are precedents is that a secondary change occurred in $\mathrm{R}_{b}$ after $\mathrm{Cl}^{-}$/gluconate substitution in the external bath. For example, in the canine bronchus, a tissue with large cellular $\mathrm{Cl}^{-}$conductance, we have observed that $R_{a} /\left(R_{a}+R_{b}\right)$ increased transiently after reduction of $\mathrm{Cl}^{-}$in the luminal bathing solution, but within 1 min $R_{a} /\left(R_{a}+R_{b}\right)$ relaxed to values close to control, in parallel with a fall in $G_{t}$ (unpublished observation). Welsh et al. also found that steadystate $\mathbf{R}_{\mathrm{a}} /\left(\mathbf{R}_{\mathrm{a}}+\mathbf{R}_{\mathrm{b}}\right)$ was unaffected when canine trachea, stimulated to secrete $\mathrm{Cl}^{-}$, was exposed to a $\mathrm{Cl}^{-}$-free luminal bathing solution (9). Such a secondary change in $\mathbf{R}_{b}$, due to time-dependent changes in intracellular ion composition or other mechanisms, may reflect homeostatic regulation of membrane permeabilities (cross-talk). An alternative explanation could be that the $\mathrm{Cl}^{-}$conductance resides in a cell type not impaled in these studies. Whereas we cannot definitively rule out this possibility, the direction of change in $\psi_{\mathrm{b}}$ and the response to isoproterenol (see below) makes this possibility unlikely.

The likelihood that the apical membrane permeability of the untreated CF apical membrane for $\mathrm{Cl}^{-}$is smaller than in NT is supported by an analysis of the interaction of amiloride treatment with the $\mathrm{Cl}^{-}$path in these tissues (Table V). The effects of amiloride exposure of airway epithelia are complex. In several respiratory epithelia (15), including NT (5), the basal Isc is equivalent to the rate of active $\mathrm{Na}^{+}$absorption. However, exposure to amiloride or replacement of luminal $\mathrm{Na}^{+}$with choline does not completely eliminate Isc. The residual Isc reflects the inducation of $\mathrm{Cl}^{-}$secretion. We have speculated that this response is due in part to a hyperpolarization of the apical membrane, which provides the driving force for a net $\mathrm{Cl}^{-}$efflux from the cell to the luminal bath (16). The presence of a relatively large $\mathrm{Cl}^{-}$current in NT during amiloride treatment therefore probably reflects in part the effects of the larger driving force $\left(\psi_{\mathrm{a}}\right)$ that favors $\mathrm{Cl}^{-}$extrusion through an apical electrodiffusive pathway (Table V). The smaller residual current in CF polyps during amiloride exposure, despite an even larger electrical driving force that favors secretion, supports the notion of a low apical membrane $\mathrm{Cl}^{-}$permeability.

Exposure of NT to the beta agonist isoproterenol appears to increase the apical cell membrane conductance for $\mathrm{Cl}^{-}$. Under conditions where the apical membrane $\mathrm{Na}^{+}$permeability was blocked with amiloride (Table III), isoproterenol increased Isc, increased $G_{t}$, and decreased $R_{a} /\left(R_{a}+R_{b}\right)$. This pattern of response is similar to that reported for isoproterenol-induced $\mathrm{Cl}^{-}$ secretion in the canine trachea $(9,13)$. With reduced $\mathrm{Cl}^{-}$in the luminal bath, isoproterenol-induced changes in NT that were also consistent with increasing the relative $\mathrm{Cl}^{-}$permselectivity of the apical membrane, e.g., $\psi_{\mathrm{a}}$ depolarized and $\mathbf{R}_{\mathrm{a}} /\left(\mathbf{R}_{\mathrm{a}}+\mathbf{R}_{\mathrm{b}}\right)$ decreased (Table IV). No changes attributable to an activation of an apical membrane $\mathrm{Cl}^{-}$permeability in response to isoproterenol exposure could be detected in CF polyp in either of the approaches (Tables III and IV). This finding is not related to an inability of CF cells to respond to beta adrenergic stimulation (17) and therefore appears to reflect a defect in the $\mathrm{Cl}^{-}$conductance in $\mathrm{CF}$.

In summary, on the basis of: (a) the abnormal response to luminal $\mathrm{Cl}^{-}$reduction with or without amiloride pretreatment; (b) the smaller residual $\mathrm{Cl}^{-}$current after amiloride exposure; and $(c)$ the failure to exhibit a detectable $\mathrm{Cl}^{-}$permeability after isoproterenol exposure, it appears that the apical membrane of the CF polyp is characterized by a markedly lower $\mathrm{Cl}^{-}$perme-

Table V. Effect of Luminal Amiloride on Transepithelial and Cellular Electric Parameters of Normal and CF Nasal Tissues

\begin{tabular}{|c|c|c|c|c|c|c|c|}
\hline Tissue & $\begin{array}{l}\text { Luminal bathing } \\
\text { solution }\end{array}$ & Isc & $\psi_{t}$ & $\psi_{\mathrm{a}}$ & $\psi_{b}$ & $\mathbf{G}$ & $\mathbf{R}_{\mathbf{a}} /\left(\mathbf{R}_{\mathbf{a}}+\mathbf{R}_{\mathbf{b}}\right)$ \\
\hline & & $u A / \mathrm{cm}^{2}$ & $m V$ & $m V$ & $m V$ & $\mathrm{mS} / \mathrm{cm}^{2}$ & \\
\hline \multirow{2}{*}{$\begin{array}{l}\text { Normal nasal turbinate } \\
(n=6)\end{array}$} & KBR & $51 \pm 11$ & $-6 \pm 2$ & $-29 \pm 3$ & $-34 \pm 2$ & $11.5 \pm 1.9$ & $0.52 \pm 0.06$ \\
\hline & $\mathrm{KBR}+$ amiloride & $17 \pm 5^{*}$ & $-2 \pm 1$ & $-38 \pm 3^{*}$ & $-39 \pm 2$ & $10.8 \pm 1.9^{*}$ & $0.57 \pm 0.07$ \\
\hline \multirow[t]{2}{*}{ CF nasal polyps $(n=6)$} & KBR & $188 \pm 24^{\ddagger}$ & $-17 \pm 1^{\ddagger}$ & $-9 \pm 4^{\ddagger}$ & $-25 \pm 4$ & $12.3 \pm 2.5$ & $0.51 \pm 0.02$ \\
\hline & $\mathrm{KBR}$ + amiloride & $9 \pm 3^{* 8}$ & $-1 \pm 0^{* \varepsilon}$ & $-32 \pm 3^{* 8}$ & $-32 \pm 3$ & $9.2 \pm 2.1^{* 8}$ & $0.69 \pm 0.04^{* \S}$ \\
\hline
\end{tabular}

Values represent mean $\pm \mathrm{SE}$ of steady-state potential and resistance. The serosal bathing solution was at all times KBR. Amiloride was added to the luminal bathing solution to achieve a final concentration of $10^{-4} \mathrm{M}$. ${ }^{*}$ Significant change induced by amiloride (paired.) ${ }^{\ddagger}$ Value for $\mathrm{CF}$ tissues is significantly different from normal tissues (unpaired). ${ }^{8}$ Change induced by amiloride is significantly different between the two tissue groups (unpaired). 
ability that cannot be activated by beta agonists. The latter observation, the inability to activate the $\mathrm{Cl}^{-}$path with isoproterenol, is consistent with the observations of Sato in the coil of the CF sweat gland (18).

We conclude that the apical barrier of CF airway epithelial cells is characterized by a decreased $\mathrm{Cl}^{-}$permeability. This inability to secrete $\mathrm{Cl}^{-}$(salt) and water could contribute to the dehydration of airway secretions reported for CF (19-21). However, the results of exposure of tissues to amiloride are also consistent with an elevated $\mathrm{Na}^{+}$conductance in CF tissues. Functionally, an increased sodium absorptive capacity, as indicated by the raised Isc, can result in increased net salt and water absorption in the presence of decreased cellular $\mathrm{Cl}^{-}$permeability only if an alternative path exists for chloride ion flow. In contrast to epithelia with high electrical resistance, e.g., sweat duct, there is an appreciable paracellular path in both CF and normal airway epithelia that allow the extracellular marker mannitol to permeate the barrier (5). The raised $\psi_{t}$ of CF airway epithelia could provide the force to drive $\mathrm{Cl}^{-}$through the paracellular path. Thus, our results suggest that the increased rate of $\mathrm{Na}^{+}$absorption (and water) by CF airway epithelia may also contribute to the "dehydration" of CF secretions.

\section{Acknowledgments}

This work was supported by National Institutes of Health grants HL22924 and HL-00787 and Cystic Fibrosis Foundation RRDP grant R002 5-02. Dr. Boucher is an Established Investigator of the American Heart Association.

\section{References}

1. Quinton, P. M. 1983. Chloride impermeability in cystic fibrosis. Nature (Lond.). 301:421-422.

2. Knowles, M., J. Gatzy, and R. Boucher. 1981. Increased bioelectric potential difference across respiratory epithelia in cystic fibrosis. $N$. Engl. J. Med. 305:1489-1495.

3. Knowles, M., J. Gatzy, and R. Boucher. 1983. Relative ion permeability of normal and cystic fibrosis nasal epithelium. J. Clin. Invest. 71:1410-1417.

4. Boucher, R. C., M. R. Knowles, C. U. Cotton, M. J. Stutts, J. R. Yankaskas, and J. T. Gatzy. 1984. On a unified theory of cystic fibrosis lung disease. In Cystic Fibrosis: Horizons. D. Lawson, editor. John Wiley \& Sons, Inc., New York. 167-177.

5. Knowles, M. R., M. J. Stutts, A. Spock, N. Fischer, J. T. Gatzy, and R. C. Boucher. 1983. Abnormal ion permeation through cystic fibrosis respiratory epithelium. Science (Wash. DC). 221:1067-1070.
6. Stutts, M. J., C. U. Cotton, J. R. Yankaskas, E. Cheng, M. R. Knowles, J. T. Gatzy, and R. C. Boucher. 1985. Chloride uptake into cultured CF and non-CF airway epithelial cells. Proc. Natl. Acad. Sci. USA. 82:6677-6681.

7. Widdicombe, J. H., and M. J. Welsh. 1985. Cystic fibrosis (CF) alters the electrical properties of monolayers cultured from cells of human tracheal mucosa. Fed. Proc. 44:136. (Abstr.)

8. Welsh, M. J., P. L. Smith, and R. A. Frizzell. 1982. Chloride secretion by canine tracheal epithelium II: the cellular electrical potential profile. J. Membr. Biol. 70:227-238.

9. Welsh, M. J., P. L. Smith, and R. A. Frizzell. 1983. Chloride secretion by canine tracheal epithelium. III. Membrane resistances and electromotive forces. J. Membr. Biol. 71:209-218.

10. Nagel, W., and P. Reinach. 1980. Mechanism of stimulation by epinephrine of active transepithelial $\mathrm{Cl}^{-}$transport in isolated frog cornea. J. Membr. Biol. 56:73-79.

11. Welsh, M. J. 1983. Intracellular chloride activities in canine tracheal epithelium. Direct evidence for sodium-coupled intracellular chloride accumulation in a chloride-secreting epithelium. J. Clin. Invest. 71: 1392-1401.

12. Reuss, L., P. Reinach, S. Weinman, and T. Grady. 1983. Intracellular ion activities and $\mathrm{Cl}^{-}$transport mechanisms in bullfrog corneal epithelium. Am. J. Physiol. 244(Suppl. 13):C336-C347.

13. Shorofsky, S. R., M. Field, and H. Fozzard. 1983. Electrophysiology of $\mathrm{Cl}$ secretion in canine trachea. J. Membr. Biol. 72:105-115.

14. Hviid-Larsen, E., and B. E. Rasmussen. 1982. Chloride channels in toad skin. Philos. Trans. R. Soc. Lond. B. Biol. Sci. 229:413-434.

15. Boucher, R. C., J. Navarte, C. U. Cotton, M. J. Stutts, M. R. Knowles, A. L. Finn, and J. T. Gatzy. 1982. Sodium absorption in mammalian airways. In Fluid and Electrolyte Abnormalities in Exocrine Glands in Cystic Fibrosis. P. M. Quinton, J. R. Martinez, and U. Hopfer, editors. San Francisco Press Inc., San Francisco, CA. 271-287.

16. Boucher, R. C., and J. T. Gatzy. 1981. Effect of amiloride and mucosal sodium removal on canine bronchial ion transport. Fed. Proc. 40:447. (Abstr.)

17. Boucher, R. C., M. J. Stutts, M. R. Knowles, L. Cantley, and J. T. Gatzy. 1986. $\mathrm{Na}^{+}$transport in cystic fibrosis nasal epithelia. Abnormal basal rate and response to adenylate cyclase activation. J. Clin. Invest. 78:1245-1252.

18. Sato, K. 1984. Differing luminal potential difference of cystic fibrosis and control sweat secretory coils, in vitro. Am. J. Physiol. 247: R646-R649.

19. Wood, R. E., T. F. Boat, and C. F. Doershuk. 1976. State of the art: cystic fibrosis. Am. Rev. Respir. Dis. 113:833-878.

20. Chernick, W. S., and G. J. Barbero. 1959. Composition of tracheobronchial secretions in cystic fibrosis of the pancreas and bronchiectasis. Pediatrics. 24:739-745.

21. Potter, J. L., L. W. Matthews, S. Spector, and J. Lemm. 1967. Studies on pulmonary secretions. II. Osmolality and the ionic environment of pulmonary secretions from patients with cystic fibrosis, bronchiectasis, and laryngectomy. Am. Rev. Respir. Dis. 96:83-87. 